\title{
Weaning down opioids in the inherited patients on high- dose opioids
}

\author{
Alaa Abd-Elsayed, ${ }^{1}$ Eric S Schwenk ${ }^{2}$
}

\section{ABSTRACT}

Patients who receive high-dose opioid therapy for chronic non-cancer pain (CNCP) are at risk for opioid dependence, misuse, and overdose death. Transitions of care between physicians complicate the situation. This retrospective study described the opioid tapering experience of one outpatient pain practice that performed a slow wean over 12 months in patients maintained at least $120 \mathrm{mg}$ of daily oral morphine equivalents for at least 6 months. The authors assessed compliance through patient history, state online prescription monitoring program, and frequent random urine toxicology screening. They reported that 57 of 91 patients who were evaluated (63\%) achieved the meaningful reduction criterion at 12 months after the transition of

\section{Regional
Anesthesia
Pain
Medicine}

Weaning down opioids in the inherited patients on high

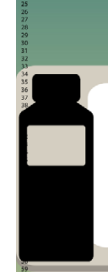
00 dose opioids

Patients who receive high-dose opioid therapy for chronic noncancer pain (CNCP) are at risk for opioid dependence, misuse, and overdose death (1).

A study by Chapman et al (2) aimed at describing the experience of individualized tapering in patients with high dose opioids after transfer of care.

Authors studied the tapering of opioids in patients with high dose opioids (for more than 6 months) after they transitioned their care.

(5)

Authors reported that of the 91 patients evaluated, 57 (63\%) achieved the meaningful reduction criterion at 12 months after the transition in care with no signifcant effect on perceived pain or daily functioning.

Authors concluded that a substantial proportion of outpatient CNCP patients on high-dose opioid therapy can be successfully tapered to a lower doses using a slow taper.

References:

1. Gomes T, Mamdani MM, Dhalla IA, Paterson JM, Juurlink DN. Opioid dose and drugrelated

mortality in patients with nonmalignant pain. Arch Intern Med 2011;171(7):686-691.

doi: 10.1001/archinternmed.2011.117.

2. Chapman K, Pas M, Akuamoah L, Deer T, Van Helmond N. Opioid Tapering Following the Transfer of Care of Outpatient Chronic Non- Cancer Pain Patients on High-Dose Opioid

Therapy.

Infographic prepared by:

Alaa Abd-Elsayed, MD, MPH, FASA

Eric Schwenn, MD care. The average reduction of daily oral morphine equivalents was $210 \mathrm{mg}$ vs $127 \mathrm{mg}$ in the groups that did and did not achieve meaningful reductions, respectively. The authors concluded that a slow taper in the ambulatory setting of patients with CNCP taking high-dose opioids can be successful in a substantial proportion of patients.

${ }^{1}$ Anesthesiology Department, University of Wisconsin Madison School of Medicine and Public Health, Madison, Wisconsin, USA

${ }^{2}$ Anesthesiology Department, Sidney Kimmel Medical College at Thomas Jefferson University, Philadelphia, Pennsylvania, USA

Correspondence to Dr Alaa Abd-Elsayed, University of Wisconsin Madison School of Medicine and Public Health, Madison, Wisconsin, USA; alaaawny@hotmail.com

Correction notice This article has been corrected since it published Online First. The second author's name has been corrected and the provenance and peer review statement has been included

Contributors All authors contributed to the design and writing of this work.

Funding The authors have not declared a specific grant for this research from any funding agency in the public, commercial or not-for-profit sectors.

Competing interests None declared.

Patient consent for publication Not required.

Provenance and peer review Commissioned; internally peer reviewed.

(C) American Society of Regional Anesthesia \& Pain Medicine 2021. No commercial re-use. See rights and permissions. Published by BMJ.

\section{(D) Check for updates}

To cite Abd-Elsayed A, Schwenk ES.

Reg Anesth Pain Med 2021;46:537-538.

Received 10 December 2020

Revised 17 December 2020

Accepted 20 December 2020

Published Online First 15 January 2021

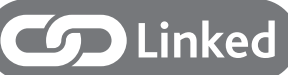

- http://dx.doi.org/10.1136/rapm-2020-102191

Reg Anesth Pain Med 2021;46:537-538.

doi:10.1136/rapm-2020-102375

\section{REFERENCES}

1 Gomes T, Mamdani MM, Dhalla IA, et al. Opioid dose and drug-related mortality in patients with nonmalignant pain. Arch Intern Med 2011;171:686-91.

2 Chapman K, Pas M, Akuamoah L. Opioid tapering following the transfer of care of outpatient chronic non- 


\section{Infographic}

